\title{
IL-3 induces a Pim1-dependent antiapoptotic pathway in primary human basophils
}

\author{
Svetlana A. Didichenko, ${ }^{1}$ Nicole Spiegl, ${ }^{1}$ Thomas Brunner, ${ }^{2}$ and Clemens A. Dahinden \\ ${ }^{1}$ Institute of Immunology and ${ }^{2}$ Institute of Pathology, University of Bern, Bern, Switzerland
}

The contribution of basophils in allergic disease and other Th2-type immune responses depends on their persistence at sites of inflammation, but the ligands and molecular pathways supporting basophil survival are largely unknown. The comparison of rates of apoptosis and of the expression of antiapoptotic proteins in different human granulocyte types revealed that basophils have a considerably longer spontaneous life span than neutrophils and eosinophils consistent with high levels of constitutive $\mathrm{Bcl}-2$ ex-

\section{Introduction}

Apoptosis of granulocytes and subsequent clearance of apoptotic cells are important processes for the successful resolution of acute and chronic inflammation. Basophils represent the least abundant granulocyte population and are considered as key effector cells in Th2-type, IgE-associated allergic disorders as well as in protective immune responses to helmints. Pro-inflammatory and immunomodulatory activities of basophils include secretion of histamine and the lipid mediator leukotriene $\mathrm{C}_{4}$ as well as rapid production of interleukin-4 (IL-4) and IL-13, Th2-type cytokines crucial for the development of allergy and asthma. Positive regulators of basophil mediator release and cytokine production have been described, whereas attempts to find negative regulators of basophil cellular functions have been unsuccessful. Therefore, the modulation of basophil apoptosis probably has a particularly high impact on the outcome of allergic inflammation.

Cytokines of granulocyte-macrophage colony-stimulating factor (GM-CSF) subfamily (GM-CSF, IL-5, and IL-3) support granulocyte survival in a granulocyte-type-restricted manner. ${ }^{1-6}$ Modulation of neutrophil and eosinophil apoptosis mediated by these cytokines has been suggested to rely on the up-regulation of antiapoptotic proteins of the Bcl-2 family, such as Bcl-2, Bcl- $\mathrm{X}_{\mathrm{L}}$, Mcl-1 and A1, ${ }^{7-9}$ as well as IAP family proteins. ${ }^{10-12}$ With regards to signaling pathways, Janus kinase (JAK)/signal transducer and activator of transcription 3 and 5 (Stat3/Stat5), phosphatidylinositol 3-kinase (PI3-kinase), as well as p38-mitogen-activated protein kinase (MAPK) have been implicated in the regulation of neutrophil and eosinophil apoptosis by GM-CSF, IL-5, and IL-3. ${ }^{13-19}$ Although previous studies showed that IL-3 prolongs the life span of basophils, ${ }^{5,6}$ there is a complete lack of knowledge about the proteins and the mechanisms that regulate spontaneous and cytokineenhanced survival of basophils. A single report suggested a requirement of PI3-kinase signaling for IL-3-mediated basophil survival. ${ }^{6}$

The mechanisms of IL-3 signaling and the involvement of downstream targets regulating cell proliferation and survival have been most thoroughly studied in leukemic human cell lines and IL-3-dependent cell lines from genetically manipulated mice. Most papers highlight the requirement of the PI3-kinase/Akt (PKB) signaling pathway and mainly differ in their interpretations about the relative importance of downstream targets, such as Bad, FOXO3, and NF-кB. ${ }^{20-24}$ These findings cannot always be transferred to human basophils or other nondividing leukocytes because the regulation of survival strongly depends on the cellular background. Furthermore, the mechanisms regulating proliferation or apoptosis are difficult to distinguish in proliferating cells, and transformed cell lines may display disturbed signaling pathways. It is thus necessary to study primary blood basophils ex vivo to understand the mechanisms regulating their survival, despite inherent experimental limitation, such as resistance to efficient transfection or the limited numbers of cells available for biochemical analysis.

The PI3-kinase/Akt pathway is central in the regulation of cell function, proliferation, and survival downstream of receptor activation by a variety of stimuli, including cytokines. ${ }^{25,26}$ Many protein kinases impact cell survival by direct or indirect contribution to PI3-kinase/Akt signaling, whereas a family of Pim kinases appears to function independently of the PI3-kinase/Akt pathway. ${ }^{27}$ Pim kinases are important mediators of cytokine signaling in hematopoietic cells 
and contribute to the progression of certain leukemias and solid tumors. ${ }^{28-31}$ Akt and Pim kinases appear to partially overlap in substrate specificity $^{32}$ and thus may play redundant roles in mediating cell growth and survival. ${ }^{33}$ Unlike most kinases, Pim1 activity is regulated at the level of gene expression mediated by Stat3/Stat5 factors, ${ }^{34-36}$ and GM-CSF-subfamily cytokines can induce Pim1 expression in primary human granulocytes ${ }^{37,38}$ A role of Pim1 in the suppression of eosinophil apoptosis by these cytokines has been suggested. ${ }^{37}$

This study is focused on the elucidation of the extracellular ligands and intracellular molecular mechanisms controlling basophil programmed cell death. We show that basophils are more resistant to spontaneous apoptosis than eosinophils and neutrophils. Among a large number of inflammatory and immunoregulatory cytokines tested, IL-3 was found to be unique and efficient in protecting basophils from apoptosis. Using pharmacologic inhibitors and a protein transduction approach, we demonstrate that IL-3 mediates its antiapoptotic effect through a Pim1-dependent pathway, providing the first evidence of a functional role of this kinase in nondividing primary cells. Thus, neutralization of IL-3 or inhibition of Pim1 kinase activity may represent potential approaches for the treatment of allergic diseases.

\section{Methods}

\section{Cell stimuli and reagents}

Recombinant rhIL-3, rhGM-CSF were obtained from Novartis (Basel, Switzerland) and rhIL-5 from Roche (Basel, Switzerland). The following inhibitors were used: LY2940002, rapamycin, and SB202190 (Alexis, Lausen, Switzerland); wortmannin (Calbiochem, San Diego, CA); and z-VAD-fmk (z-Val-Ala-DL-Asp(OMe)-fluromethylketone; Bachem, Bubendorf, Switzerland)

\section{Cells and cell culture}

Approval for using blood from healthy adult volunteers was obtained from the ethical committee of the State of Bern. Informed consent was obtained in accordance with the Declaration of Helsinki. Basophils, eosinophils, and neutrophils were purified as described previously. ${ }^{38}$ Purity of different granulocyte populations ranged between $95 \%$ and $99 \%$ as determined by Giemsa-May-Grünwald staining of cytospin preparations. Granulocytes were cultured at 1 to $2 \times 10^{6}$ cells per milliliter in a complete culture medium (RPMI 1640 containing $2 \mathrm{mM}$ L-glutamine, $25 \mathrm{mM} \mathrm{N}-2$ hydroxyethylpiperazine- $\mathrm{N}^{\prime}$-2-ethanesulfonic acid (Invitrogen, Carlsbad, CA), supplemented with $10 \%$ heat-inactivated FCS (Seromed, Berlin, Germany), and antibiotics (100 IU/mL penicillin, $100 \mu \mathrm{g} / \mathrm{mL}$ streptomycin; Amimed, Basel, Switzerland), and incubated in 96-well U-bottom tissueculture plates at $37^{\circ} \mathrm{C}$ in a humidified atmosphere of $5 \% \mathrm{CO}_{2}$. After incubation with or without stimuli as indicated, cells were harvested for apoptosis assay and Western blotting.

\section{Apoptosis assay}

For assessment of apoptosis, cells were stained with propidium iodide (PI; Sigma-Aldrich, St Louis, MO) and fluorescein isothiocyanate (FITC)annexin V (BD Biosciences, San Jose, CA) according to the manufacturer's protocol. Flow cytometry was performed with a FACSCalibur (BD Biosciences). The data of at least $10^{4}$ cells were acquired. Annexin-V/PInegative cells were defined as live cells and presented as a percentage of total cells. In inhibitor and protein transduction experiments, apoptotic cells defined as annexin V-positive cells were analyzed. All experiments were performed in duplicates or triplicates. The data are shown as mean plus or minus SEM of at least 3 independent experiments.

\section{Statistical analysis}

Comparisons of groups were performed using Student $t$ test, 1-way or 2-way analysis of variance (ANOVA) with the Bonferroni posttest as appropriate. $P$ values less than .05 were considered statistically significant.

\section{Western blot analysis}

Western blotting was performed as described previously. ${ }^{38}$ Antibodies to cIAP-2, Granzyme B, and Pim1 were from Santa Cruz Biotechnology (Santa Cruz, CA); anticleaved caspase 3, antiprocaspase 3, antiphosphop38 (Thr180/Tyr182), anti-p38, antiphospho-Stat5 (Tyr694) antibodies were from Cell Signaling Technology (Danvers, MA). Anti-XIAP and anti-Mcl-1 antibodies were from BD Biosciences, anti-Bcl- $X_{\mathrm{L}}$ antibody was from R\&D Systems (Minneapolis, MN), anti-Bcl-2 antibody was from Dako North America (Carpinteria, CA). Anti-HA (12CA5) monoclonal antibody was from Roche Diagnostics. Secondary horseradish peroxidaseconjugated goat antimouse or goat antirabbit antibodies were from Bio-Rad (Hercules, CA). For loading controls, stripped membranes were incubated with an anti- $\beta$-actin antibody (Sigma-Aldrich). Immunoreactive bands were visualized using enhanced chemiluminescence detection system (ECL-Kit; Pierce Chemical, Rockford, IL) and Luminescent Image Analyzer (LAS3000; Fujifilm, Tokyo, Japan). The quantitative analysis was performed using AIDA software (Fujifilm). Western blot analysis was performed at least 3 times using cells from different donors. Representative experiments are shown.

\section{Expression and purification of TAT-Pim1(wt) and TAT-Pim1(KD) fusion proteins}

Plasmids encoding wild-type (wt) human Pim1 were provided by Dr B. Turk (Yale University School of Medicine, New Haven, CT) and Dr A. Bullock (Oxford University, Oxford, United Kingdom). For generation of the Tat-Pim1 fusion proteins, cDNA encoding HA-Pim1(wt) or HAPim1(KD) were subcloned into pTAT 2.1 expression vector in frame between N-terminal Tat (YGRKKRRQRRR) and C-terminal $\mathrm{His}_{6}$-tag sequences. pTAT 2.1 was provided by $\operatorname{Dr}$ S. Dowdy (University of California, San Diego). HA-Pim1 cDNA was generated by PCR amplification, HA-tag (MAYPYDYPDYASL) was introduced at the N-terminus of Pim1. To generate Pim1 kinase dead (KD), ${ }^{39,40}$ Lys67 was replaced with Met in Pim1(wt) using a PCR-based site-directed mutagenesis strategy. TAT-Pim1 expression vectors were transformed into BL21/DE3 Escherichia coli strain. Overnight cell culture was diluted with fresh LB medium, cells were grown up to an optical density of 0.6 to 0.7 at $600 \mathrm{~nm}$, and TAT-Pim1 expression was induced with isopropyl-b-D-thiogalactopyranoside $0.1 \mathrm{mM}$ at $30^{\circ} \mathrm{C}$ for 4 hours. Cells expressing TAT-Pim1(wt) were resuspended in buffer A (20 mM Tris, pH 7.9, $0.5 \mathrm{M} \mathrm{NaCl}, 20 \mathrm{mM}$ imidazole) supplemented with protease inhibitors (complete inhibitor set [Roche] and $100 \mu \mathrm{g} / \mathrm{mL}$ Pefabloc [Sigma-Aldrich]), and disrupted by sonication using a Branson Sonifier 250. Soluble fraction was recovered by centrifugation at $14000 \mathrm{~g}$ for 20 minutes, and TAT-Pim1(wt) was purified under native conditions using $\mathrm{Ni}^{2+}$ affinity resin (QIAGEN, Valencia, CA) according to the manufacturer's instructions. Fusion protein was eluted with $100 \mathrm{mM}$ imidazole in buffer A and dialysed against phosphate-buffered saline ( $\mathrm{pH}$ 7.4) containing 10\% glycerol. TATPim1(KD) was purified under denaturating conditions. Inclusion bodies were solubilized in buffer B ( $8 \mathrm{M}$ urea, $20 \mathrm{mM}$ Tris, pH 7.9, $0.5 \mathrm{M} \mathrm{NaCl}, 20$ $\mathrm{mM}$ imidazole) and applied on $\mathrm{Ni}^{2+}$ resin. TAT-Pim1(KD) was eluted with buffer B containing $100 \mathrm{mM}$ imidazole. Urea and imidazole were removed from the protein solution by dilution of the protein mixture 4 times, which was followed by dialysis against phosphate-buffered saline, $\mathrm{pH} 7.4$, containing $10 \%$ glycerol. More details about the cloning and characteristics of the fusion proteins are provided in Document S1 (available on the Blood website; see the Supplemental Materials link at the top of the online article).

Before protein transduction, basophils were resuspended at 2 to $3 \times 10^{6}$ cell $/ \mathrm{mL}$ and plated into 48 -well flat-bottom plates (10\% $/$ well). Purified TAT-Pim1 $1 \mathrm{wt}$ ) and Tat-Pim1(KD) fusion proteins were added directly to the cultured cells at $20 \mu \mathrm{g} / \mathrm{mL}$. This concentration was used because preliminary experiments revealed that lower concentrations of fusion proteins do 
Figure 1. Spontaneous and cytokine-mediated survival of basophils in comparison to eosinophils and neutrophils. (A) Time course evaluation of spontaneous apoptosis and effects of GM-CSF, IL-5, and IL-3 on granulocyte survival. Granulocytes were cultured for 0 to 72 hours in the absence or presence of the cytokine indicated (all at $50 \mathrm{ng} / \mathrm{mL}$ ), and apoptosis was assessed by double staining of cells with annexin V-FITC and propidium iodide $(\mathrm{PI})$. Live cells are shown as percentage of annexin V/PI-negative cells. Data are from 4 independent experiments and shown as the mean plus or minus SEM. The $P$ values show the levels of probability for differences between the indicated treatments (two-way ANOVA). Significantly different from the mean value of the control: ${ }^{\star} P<.05,{ }^{\star \star} P<.01,{ }^{\star \star \star} P<.001$, cytokine versus medium. (B) A comparative Western blot analysis of the expression of proteins regulating apoptosis in granulocytes. Granulocytes were freshly isolated (Fr.is.) or cultured for 24 hours in medium alone without or with the indicated cytokines. Equal amounts $(20 \mu \mathrm{g})$ of protein extracts derived from different granulocyte subtypes were resolved by SDS-PAGE and immunoblotted using specific antibodies recognizing clAP2, XIAP, Mcl-1, Bcl$\mathrm{X}_{\mathrm{L}}, \mathrm{Bcl}-2$, PARP, and caspase 3. $\beta$-Actin is shown as loading control. (C) Spontaneous apoptosis of basophils is regulated through a caspase-dependent mechanism. Basophils were cultured in the absence or presence of the pan-caspase inhibitor zVAD-fmk $(30 \mu \mathrm{M})$ or IL-3 $(50 \mathrm{ng} / \mathrm{mL})$. (Left panel) Apoptosis was evaluated by flow cytometry using annexin V-FITC staining after 24 hours or 48 hours of culture. Apoptotic cells are shown as percentage of annexin V-positive cells. Results of 5 independent experiments are reported as the mean plus SEM. ${ }^{*} P<.05$ for comparison of the treatment with medium control, by 1-way ANOVA. (Right panel) Western blot analysis of caspase 3 activation and caspase substrate cleavage (BCL-2, PARP) in protein extracts derived from basophils cultured for 24 hours.
A

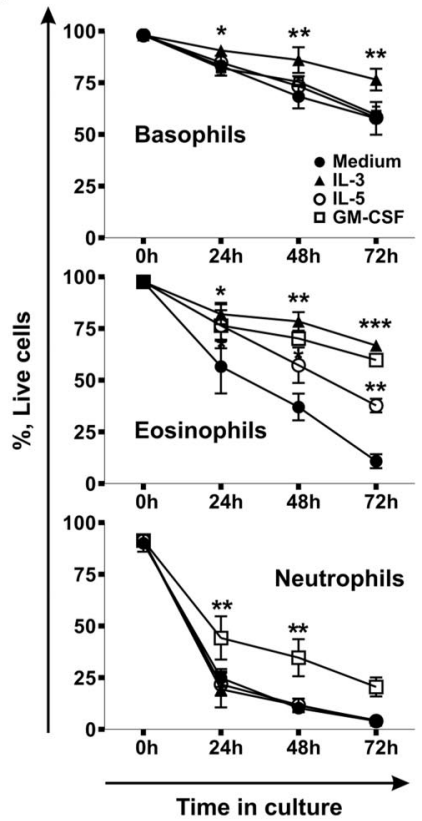

B

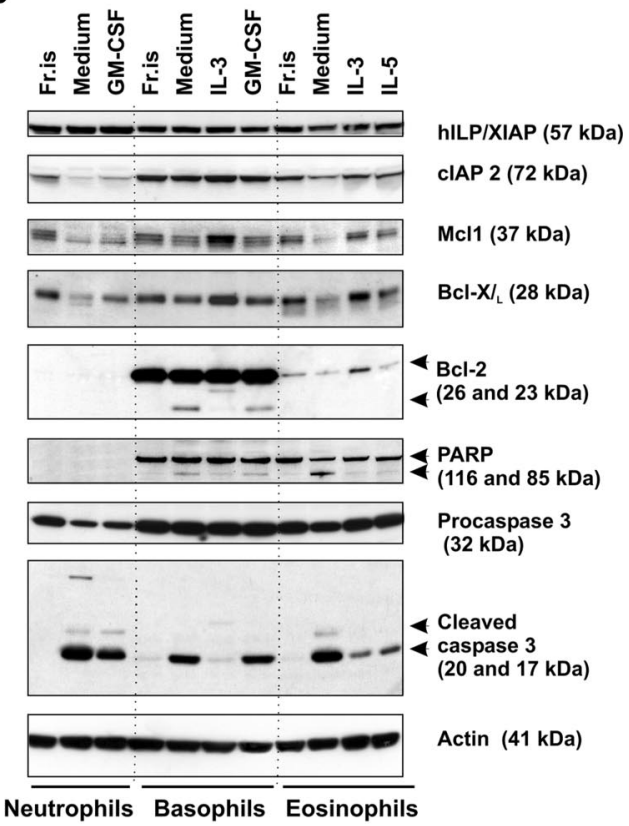

C

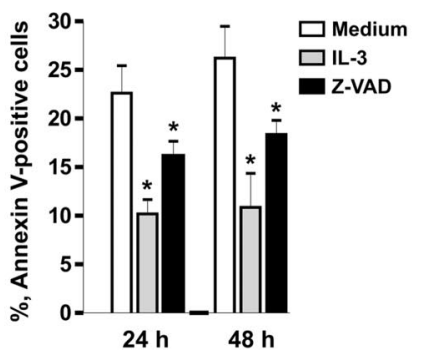

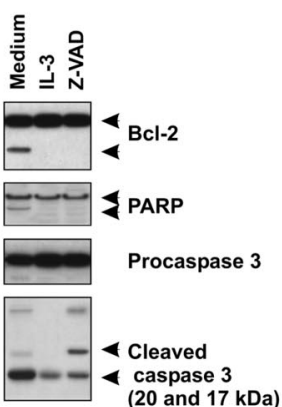

not have a significant impact on caspase 3 activation compared with nontransduced control cells (Figure S5). During 24 hours of transduction, fusion proteins were added each 4 to 6 hours. Addition of the inhibitors to the cells followed 1 hour after the addition of the fusion proteins; wortmannin was readded to the cells every 4 hours. The uptake of TAT-tagged proteins was analyzed by Western blotting. Protein transduction was carried out either in the presence of IL-3, or basophils were treated first with IL-3 $(50 \mathrm{ng} / \mathrm{mL})$ for 16 to 18 hours, washed twice with warm fresh medium without IL-3, and then transduced with TAT-Pim1 fusion proteins.

\section{Results}

\section{Human blood basophils are long-lived cells expressing high} levels of $\mathrm{Bcl}-2$

Without activation signals, neutrophils and eosinophils are shortlived cells, whereas little is known about the life span of basophils. We compared the rates of spontaneous apoptosis of the different granulocyte types in time-course experiments by measuring phosphatidylserine externalization and evaluated the effectiveness of the hematopoietins, GM-CSF, IL-5, and IL-3, to support granulocyte survival in vitro. Figure 1A shows that the majority of neutrophils underwent spontaneous apoptosis within 24 hours of culture. Eosinophils had a lower rate of apoptosis than neutrophils, but basophils were most resistant to apoptosis. Close to $60 \%$ of basophils stayed alive after 3 days in culture when almost all neutrophils and eosinophils died. Among the 3 GM-CSF family members known to regulate basophil functions, ${ }^{41-45}$ only IL-3 efficiently protected basophils from apoptosis, whereas GM-CSF and IL-5 had no significant effect. IL-3, IL-5, and GM-CSF all prolonged the life span of eosinophils, whereas only GM-CSF enhanced neutrophil survival. Thus, in eosinophils and neutrophils, the effectiveness of the cytokines to mediate survival appears to correspond to the expression profile of the receptor alpha-chains, whereas additional factors, such as the duration and the intensity of cytokine signaling (Figure S1), might be important for basophil survival.

Low susceptibility of basophils to spontaneous apoptosis and their high resistance to cell death in the presence of IL-3 clearly indicated that an intrinsic suicide program in these cells could be more effectively balanced by survival signals compared with other types of granulocytes. We analyzed by Western blotting the constitutive and cytokine-induced expression of antiapoptotic members of Bcl-2 and IAP families in different granulocytes. Figure 1B shows that freshly isolated granulocytes express similar levels of cIAP2, XIAP, Mcl-1, and $\mathrm{Bcl}-\mathrm{X}_{\mathrm{L}}$ proteins. Bcl-2 was absent from neutrophils, barely detectable in eosinophils, but prominently expressed in basophils. Compared with freshly isolated cells, levels of cIAP2, Mcl-1, and Bcl- $\mathrm{X}_{\mathrm{L}}$ were reduced in granulocytes cultured in medium alone but stayed constant or even increased on incubation of cells with prosurvival cytokines. In contrast, XIAP levels were not affected. Reduced survival of basophils cultured in medium alone 
A
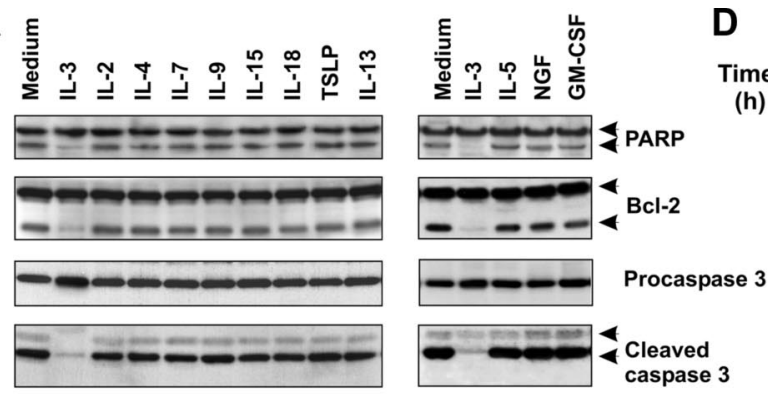

B

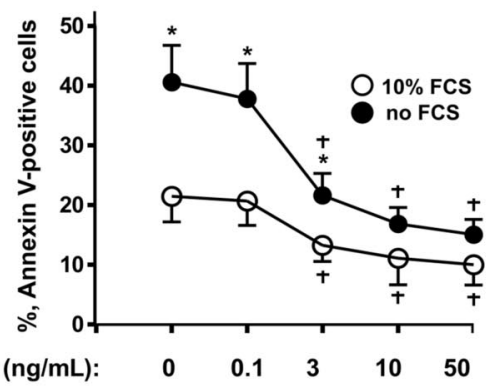

$\mathbf{F}$
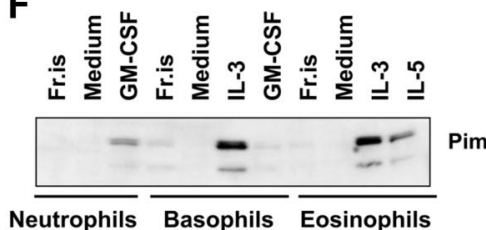

IL-3 (ng/mL):

C

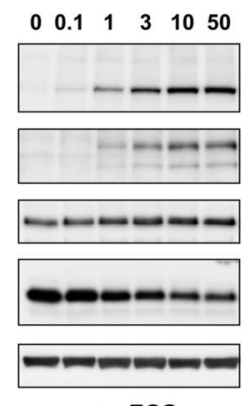

no FCS $\begin{array}{lllllll}0 & 0.1 & 1 & 3 & 10 & 50 & : \mathrm{lL}-3 \\ (\mathrm{ng} / \mathrm{mL})\end{array}$

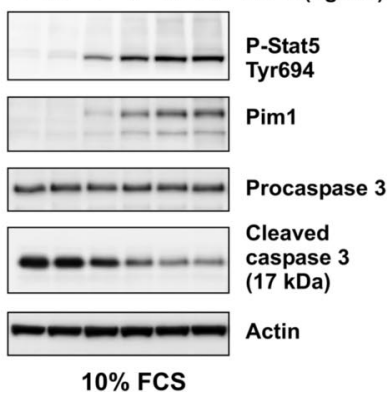

E

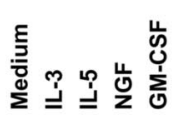

D

(ime: $\begin{array}{lllllll}0 & 1 & 2 & 4 & 8 & 20 & 40\end{array}$

(h)

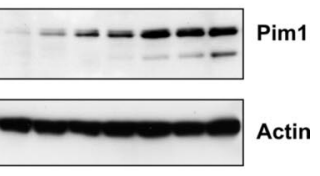

Pim1
Neutrophils Basophils Eosinophils
Figure 2. IL-3 induces Pim1 protein expression in basophils. (A) Effects of immunoregulatory and proinflammatory cytokines on basophil apoptosis. Basophils were cultured for 24 hours in the absence or presence of the indicated cytokines. Activation of caspase 3dependent cascade evidenced by procaspase 3, PARP, and $\mathrm{Bcl}-2$ proteolytic cleavage was determined by immunoblotting. Cytokines were used at the following concentrations: $20 \mathrm{ng} / \mathrm{mL}$ (IL-3, IL-2, IL-4, IL-7, IL-9, IL-13, IL-15, and TSLP), $50 \mathrm{ng} / \mathrm{mL}$ (IL-5, GM-CSF, and NGF). $(B, C)$ IL-3 supports basophil survival and induces Pim1 protein expression under serum-free and serum-containing culture conditions. (B) Basophils were cultured in serum-free medium (RPMI supplemented with $1 \mathrm{mg} / \mathrm{mL}$ of BSA) or in serum-containing medium (RPMI supplemented with $10 \%$ FCS) for 24 hours in the presence of increasing concentrations of IL-3 $(0-50 \mathrm{ng} / \mathrm{mL})$ as indicated. Apoptosis was evaluated by annexin V-FITC staining. Data are from 3 independent experiments and presented as the mean plus or minus SEM. ${ }^{*} P<.05$ for comparison of no FCS versus $10 \%$ FCS. $\dagger P<.05$ for IL-3 treatment versus medium control, by ANOVA. (C) Dose-response of Pim1 induction by IL-3. Pim1, procaspase 3 , activated caspase 3 , as well as phosphorylation status of Stat 5 were analyzed by Western blotting using specific antibodies. $\beta$-Actin is shown as loading control. (D) Time-course analysis of Pim1 protein expression induced in basophils by IL-3. Basophils were incubated in the presence of IL-3 $(50 \mathrm{ng} / \mathrm{mL})$ for indicated time periods. Pim1 protein expression was analyzed by immunoblotting. (E) Comparison of the effects of priming cytokines on Pim1 expression in basophils. Basophils were cultured for 24 hours with IL-3, IL-5, GM-CSF, or NGF (all at $50 \mathrm{ng} / \mathrm{mL}$ ) before analysis of Pim1 by Western blotting. (F) Pim1 is induced in human granulocytes on stimulation with prosurvival cytokines of the GM-CSF family. Freshly isolated granulocytes (Fr.is.) or cells cultured for 24 hours in medium alone or in the presence of the indicated cytokine (all at $50 \mathrm{ng} / \mathrm{mL}$ ). See also Pim1 expression in neutrophils and eosinophils cultured with all members of the GM-CSF family in Figure S2. or with GM-CSF was associated with the appearance of the truncated proapoptotic form of Bcl-2 (23 kDa), but not with the reduction of the full-length $\mathrm{Bcl}-2$ expression. These findings suggest that the comparatively high resistance of basophils to spontaneous apoptosis might be related to the high level of constitutive Bcl-2 expression.

\section{Spontaneous basophil apoptosis involves activation of caspases}

Caspases have been shown to promote apoptosis of neutrophils ${ }^{46}$ and eosinophils. ${ }^{47,48}$ We thus investigated whether spontaneous apoptosis of basophils also involves caspase activation. Figure 1B demonstrates that in basophils, similar to other granulocytes, the reduction in cell viability was accompanied by an increase in the level of activated caspase 3. In basophils and in eosinophils, activation of the caspase 3 cascade resulted in cleavage of $116 \mathrm{kDa}$ poly(ADP-ribose) polymerase (PARP) into a $85-\mathrm{kDa}$ fragment. Consistent with the previous reports, no PARP was detected in neutrophils. ${ }^{49}$

To investigate the role of caspase 3 in basophil apoptosis, we used the broad-spectrum caspase inhibitor z-VAD-fmk. As illustrated in Figure 1C, $\mathrm{z}$-VAD-fmk enhanced survival of cultured basophils and suppressed caspase 3 processing into its catalytically active p17 form and subsequent cleavage of PARP and Bcl-2. However, whereas IL-3 acted upstream of initial procaspase 3 processing, z-VAD-fmk altered the caspase 3 cleavage profile by blocking the final autocatalytic step as evidenced by the accumula- tion of the partially processed p20 form. These results indicate that, during apoptosis, phosphatidylserine externalization is dependent on caspase activation and implicates caspase 3 as an effector of the execution of spontaneous apoptosis in basophils. The measurement of the levels of the cleaved $17-\mathrm{kDa}$ form of active caspase 3 proved to be a very sensitive and reliable tool to monitor early basophil apoptosis after 24 hours of culture when the numbers of early apoptotic cells as assessed by annexin V staining were still small.

\section{IL-3 is a unique basophil survival factor that induces a rapid and sustained de novo expression of Pim1 protein}

Next, we examined whether other cytokines produced during inflammatory responses by activated mast cells and $\mathrm{T}$ lymphocytes are able to sustain basophil survival in culture. Caspase 3 activation was measured as a marker of early stages of apoptosis. Figure 2A shows that, besides IL-3, none of the 11 cytokines listed, including the basophil priming factors, IL-5, GM-SCF, and NGF, ${ }^{41-45}$ efficiently prevented the generation of active caspase 3 and PARP/ $\mathrm{Bcl}-2$ cleavage. Analysis of cell apoptosis using annexin $\mathrm{V}$ staining (not shown) confirmed that, with the exception of IL-3, the cytokines tested exert no or minimal effects on basophil life span. A further screen of the antiapoptotic potential of other stimuli, such as LPS, IL-1 $\beta$, TNF- $\alpha$, IL-6, IL-10, IFN- $\gamma$, including basophil agonists such as C5a, MCP-1, and eotaxin, demonstrated that none of them supported basophil survival. The ability of IL-3 to support basophil survival was also observed under serum-free culture conditions (Figure 2B). 
We have previously demonstrated that IL-3 induces the expression of protein kinase Pim1 in human basophils, ${ }^{38}$ although its function was not examined. In light of the proposed role of Pim1 as a regulator of cell proliferation/survival in several types of cells, we studied whether Pim1 may contribute to the cytokine-mediated survival in primary basophils. We analyzed Pim1 protein expression in time-course and dose-response experiments with IL-3. Figure 2C demonstrates that IL-3 induced sustained Stat 5 activation and de novo Pim1 expression and suppressed caspase 3 activation in the same dose-dependent manner under serumcontaining and serum-free culture conditions. The induction of Pim1 by IL-3 was rapid and prolonged (Figure 2D). The protein was already detectable at 1 hour of stimulation of basophils with IL-3, reached a maximum at 8 hours, and remained elevated thereafter. These results, together with the observation that Pim1 was de novo induced only on stimulation with a pro-survival cytokine in all types of granulocytes (Figures 2E,F and S2), suggest a role of Pim1 in promoting granulocyte survival.

\section{IL-3 activates a PI3-kinase-independent antiapoptotic pathway in basophils}

Previously, it has been reported that IL-3 prevents apoptosis in human basophils through activation of PI3-kinase. ${ }^{6}$ This conclusion was based on the observation that the commonly used PI3-kinase pharmacologic inhibitor LY294002 blocked IL-3induced survival. Recent findings that LY294002 inhibits the catalytic activity of Pim $1^{50}$ suggest that the impact of PI3-kinase on IL-3-mediated basophil survival might have been overestimated. To delineate the roles of PI3-kinase and Pim1 in regulating spontaneous and IL-3-enhanced survival of basophils, we compared the effects of 2 PI3-kinase inhibitors, wortmannin and LY294002, and examined the involvement of the mTOR pathway downstream of PI3-kinase using rapamycin. Wortmannin and LY294002 were used at $100 \mathrm{nM}$ and $30 \mu \mathrm{M}$, respectively. These concentrations were effective in blocking the IL-3-induced transient activation of PKB downstream of PI3-kinase as determined in short-term stimulation experiments (Figure S3). Figure 3A shows that rapamycin had no effect on cell survival regardless of the presence of IL-3, demonstrating that mTOR signaling does not control basophil survival. In cells cultured in medium alone, wortmannin and LY2940002 enhanced the rate of apoptosis and caspase 3 activation to the same extent indicating that spontaneous survival of basophils is regulated by PI3-kinase. However, in the presence of IL-3, basophils were clearly less sensitive to wortmannin than to LY294002 (Figure 3). Indeed, the relative enhancement of survival mediated by IL-3 in wortmannin-treated cells was close to that of cells cultured without inhibitors, suggesting that the IL-3-mediated survival signal is largely independent on PI3kinase. This implies that IL-3 induces de novo synthesis and/or activation of a LY294002-sensitive antiapoptotic kinase. Western blot analysis confirmed that the drugs were active, blocking IL-3induced expression of granzyme B. ${ }^{38}$ However, the inhibitors did not affect the IL-3-mediated sustained Stat5 activation and hardly suppressed induction of Pim1 expression (Figure 3B). Taken together, our data support the hypothesis that Pim1 is the LY294002-sensitive kinase mediating IL-3-enhanced survival in human basophils.

\section{TAT-Pim1(KD) inhibits the antiapoptotic effect of IL-3}

To directly test whether Pim1 can regulate the survival of primary basophils, we introduced wt and KD Pim1 proteins into basophils using a protein transduction approach. Cell-permeable Pim1 chime-
A

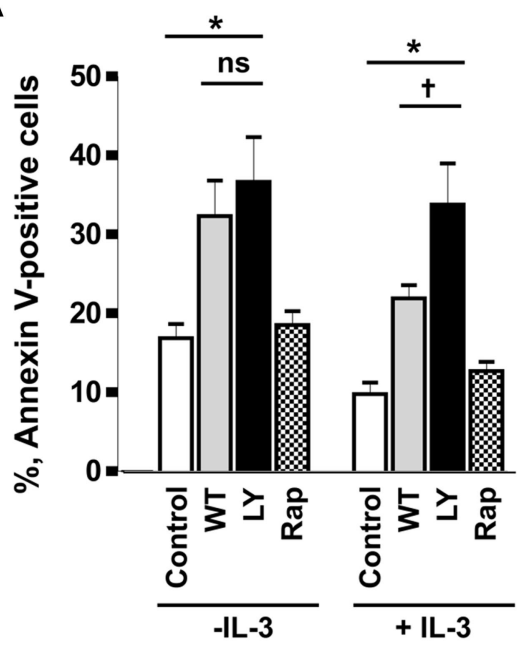

B

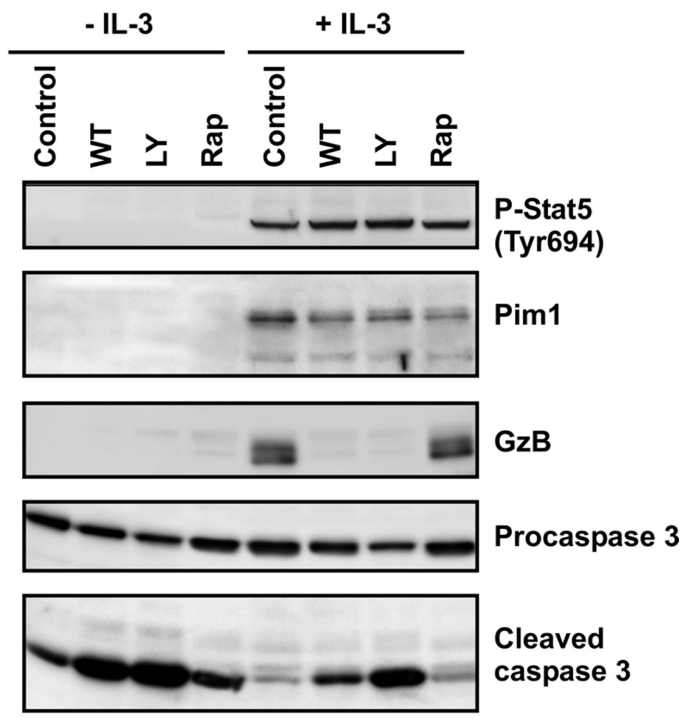

Figure 3. IL-3 induces a PI3-kinase-independent antiapoptotic pathway in basophils. $(A, B)$ Basophils were stimulated or not with IL-3 $(50 \mathrm{ng} / \mathrm{mL})$ for 24 hours in the absence (Control) or presence of different inhibitors: PI3-kinase inhibitors, LY2940002 (LY, $30 \mu \mathrm{M})$, and wortmannin (WT, $100 \mathrm{nM}$ ); mTOR inhibitor, rapamycin (Rap, $50 \mu \mathrm{M}$ ). Inhibitors were added 30 minutes before the addition of IL-3. (A) The percentage of apoptotic (annexin V-positive) cells is shown. Data are from 5 independent experiments and reported as the mean plus SEM. ${ }^{\star} P<.05$ for comparison of the treatment with medium control. ns indicates not significant for comparison of WT versus $L Y$ in medium. $† P<.05$, WT versus $L Y$ in the presence of IL-3, by 1-way ANOVA. (B) Procaspase 3, activated caspase 3, granzyme B (GzB), and Pim1 as well as phosphorylation of Stat 5 were analyzed by Western blotting using specific antibodies.

ras were generated by fusion with an HIV-1 TAT peptide (YGRKKRRQRRR; Figure 4A) known to mediate uptake of coupled targets into the cells. ${ }^{51}$ Sodium dodecyl sulfate-polyacrylamide gel electrophoresis (SDS-PAGE) followed by Coomassie blue staining indicated that they were essentially homogeneous (Figure 4B). Kinasedead Pim1 mutant, Tat-Pim1(KD), in which the Lys67 was replaced with Met, exhibited a slightly faster electrophoretic mobility than Tat-Pim1 (wt) because of the lack of autophosphorylation (Figure S4).

Figure 4C illustrates that TAT-Pim1(KD) blocks the ability of IL-3 to enhance basophil survival. Basophils transduced with TAT-Pim1(KD) for 24 hours in the presence of IL-3 showed increased levels of apoptosis and caspase 3 activation compared with IL-3-stimulated cells, which were either left untreated or transduced with TAT-Pim1(wt) (Figure 4D). The data suggest that 
A

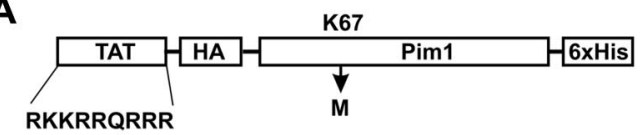

B

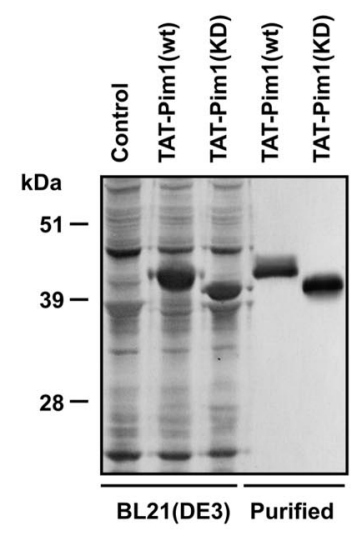

C

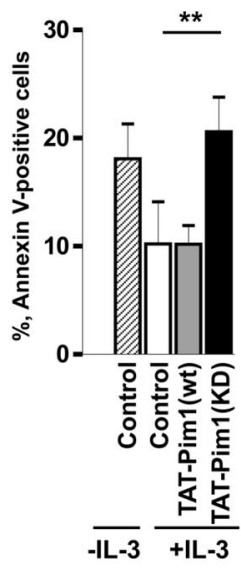

D
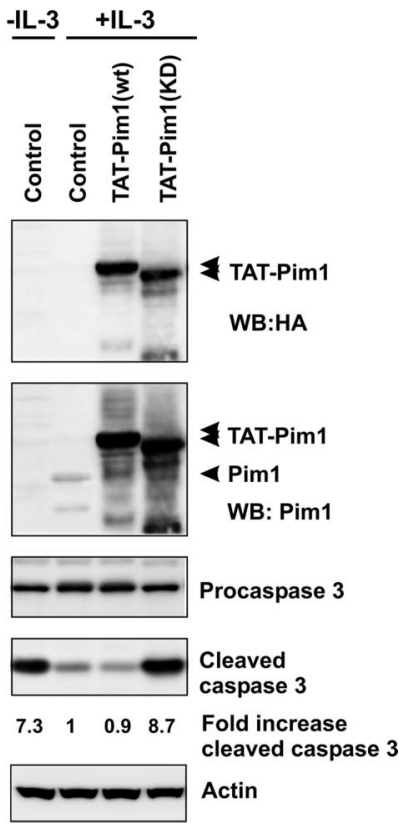

Figure 4. Kinase-dead Pim1 inhibits IL-3-induced basophil survival. (A) Schematic diagram representing the structure of TAT-Pim1(wt) and TAT-Pim1(KD). TAT peptide precedes the HA-tag at the $\mathrm{N}$-terminus of Pim1, 6 His residues are located at the $\mathrm{C}$-terminus of fusion protein. Kinase dead mutant Pim1(KD) has a single amino acid substitution of Lys67 to Met (K67M). (B) Expressed in E coll BL21(DE3) and further purified TAT-Pim1(wt) and TATPim1(KD) fusion proteins were analyzed by SDS-PAGE followed by Coomassie blue staining. (C,D) Basophils were treated with buffer (control) or transduced with TAT-Pim1(wt) or TAT-Pim1 (KD) as indicated and cultured in the presence of IL-3 for 24 hours. Cells cultured in the absence of IL-3 are shown as controls. (C) Apoptosis was determined by annexin V-FITC staining and flow cytometry. Data are shown as mean plus SEM from 3 experiments. ${ }^{\star *} P<.01$ for comparison of IL-3 control versus TAT-Pim1(KD) + IL-3. (D) Activation of caspase 3 was assessed by immunoblotting for procaspase 3 and cleaved caspase 3 . TAT-Pim1 fusion proteins were detected using anti-HA antibody and after the stripping with anti-Pim1 antibody. $\beta$-Actin was used as loading control. Fold change of caspase 3 activity was calculated as relative ratio of the band intensity value of cleaved caspase 3 in individual sample divided by the band intensity value of cleaved caspase 3 from control IL-3treated basophils. The band intensity values of cleaved caspase 3 were normalized to $\beta$-actin.
Tat-Pim1(KD) mutant counteracts the activity of endogenous Pim1 in IL-3-stimulated basophils in a dominant negative manner by competing for upstream activators and/or downstream targets. The observation that TAT-Pim1(wt) does not further increase the prosurvival effect of IL-3 suggests that the Pim1-dependent survival program is at a maximum of activation.

\section{TAT-Pim1(wt) confers apoptotic resistance independently of PI3-kinase}

To evaluate the ability of Pim1 to enhance apoptotic resistance of basophils to wortmannin, we transduced TAT-Pim1 fusion proteins into basophils deprived of IL-3 in the absence or presence of wortmannin or LY294002. Data summarized in Figures 5A,B and S5 show that, at 24 hours after transduction, Tat-Pim1(wt), but not Tat-Pim1(KD), was able to reduce caspase 3 activation and to protect cells from spontaneous apoptosis in the absence of drugs, although to a lesser degree than IL-3. TAT-Pim1 (wt) attenuated basophil apoptosis in the presence of wortmannin but failed to suppress the proapoptotic effect of LY294002. In marked contrast to TAT-Pim1(wt), kinase-dead mutant Tat-Pim1(KD), which is incapable of phosphorylating downstream targets, did not protect basophils from apoptosis. Taken together, these results demonstrate that the catalytic activity of Pim1 promotes basophil survival independently of PI3-kinase.

\section{The Pim1-dependent antiapoptotic pathway involves activation of p38 MAPK}

The serine/threonine kinase p38 MAPK has been recently shown to contribute to survival of human and mouse granulocytes. ${ }^{19,52}$ Surprisingly, we found that the transduction of basophils with TAT-Pim1(wt) caused an increase in activating phosphorylation of p38 MAPK at Thr180/Tyr182 residues similar to that seen in IL-3-stimulated cells (Figure 5C). No such effect was observed in cells transduced with the TAT-Pim1(KD) mutant indicating that the enhancement in p38 MAPK activation depends on the kinase activity of Pim1. LY294002, but not wortmannin, suppressed p38 MAPK phosphorylation in control cells as well as in cells transduced with TAT-Pim1 proteins (Figure 5C). Thus, activation of p38 MAPK in basophils appears to be independent on PI3-kinase as evidenced by the lack of an inhibitory effect of wortman- nin on p38 MAPK activation. However, because in control LY294002treated cells p38 MAPK phosphorylation drops below a basal level seen in control untreated cells, it is possible that, besides Pim1, there is another LY294002-sensitive target responsible for the basal activity of p38 MAPK.

To evaluate the significance of p38 MAPK activation in mediating enhanced basophil survival and to determine whether Pim1 exerts its antiapoptotic effect by activating the p38 MAPK pathway, we tested whether the specific inhibitor of p38 MAPK $\alpha$ and $\beta$ isoforms, SB202190, can modulate basophil survival and inhibit the antiapoptotic effect of Tat-Pim1(wt). Basophils cultured without IL-3 were transduced with TAT-Pim1 fusion proteins in the absence or presence of SB202190 or wortmannin. Figure 6 shows that SB202190 attenuated an antiapoptotic effect of TAT-Pim1(wt), causing a similar degree of apoptosis in control cells and cells transduced with either wild-type or kinase-dead TAT-Pim1 fusion proteins (Figure 6A). The extent of apoptosis and the level of caspase 3 activation in SB202190-treated cells were close to that observed in control cells treated with wortmannin (Figure 6B). The level of p38 MAPK phosphorylation was unaffected by SB202190, indicating that, in basophils, the activation of this kinase is not mediated by its autocatalytic activity (Figure 6C). These results suggest that the antiapoptotic effect of Pim1 is mediated through p38.

\section{Discussion}

The survival of basophils and their persistence at sites of allergic inflammation are expected to contribute to the pathology of chronic allergic diseases and asthma. Induction of apoptosis might therefore represent an important mechanism to eliminate basophils from the tissues to achieve the successful resolution of allergic inflammation. We demonstrate the blood basophils represent the granulocyte type that is most resistant to spontaneous apoptosis. Contrary to a previous report, ${ }^{6}$ but consistent with findings of other investigators, ${ }^{45,53}$ we found that the half-life of basophils in culture is approximately 3 days in the absence of prosurvival cytokines, in marked contrast to neutrophils and eosinophils, which undergo spontaneous apoptosis within 24 hours. Comparative analysis of the expression of antiapoptotic proteins revealed that different types of granulocytes constitutively express similar levels of 
A

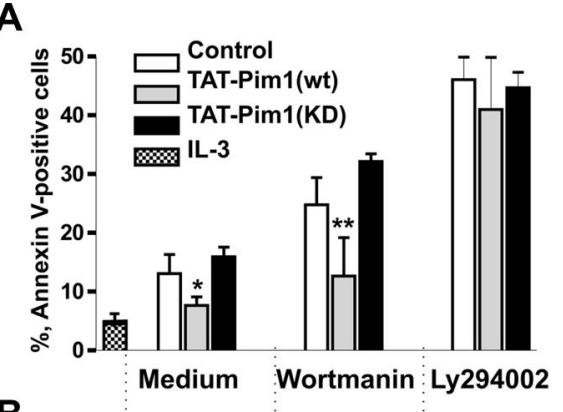

B
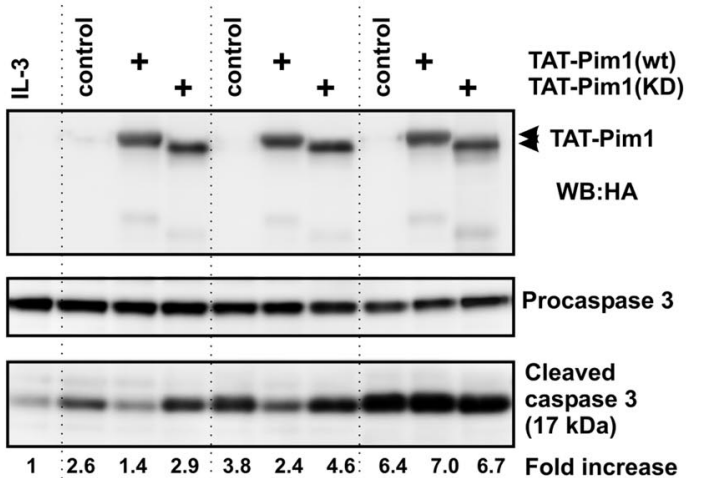

Cleaved

caspase 3 (17 kDa)

$\begin{array}{llll:lllllll}1 & 2.6 & 1.4 & 2.9 & 3.8 & 2.4 & 4.6 & 6.4 & 7.0 & 6.7 & \text { Fold increase }\end{array}$ cleaved caspase 3

C
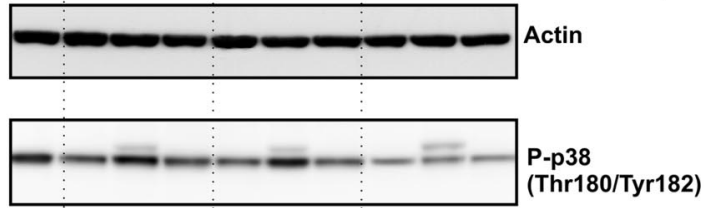

$\begin{array}{llll:lll:llll}1 & 0.5 & 1.0 & 0.6 & 0.6 & 0.8 & 0.6 & 0.2 & 0.3 & 0.2 & \text { Fold increase }\end{array}$ P-p38

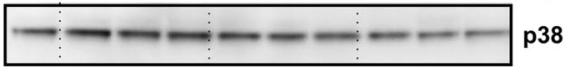

Figure 5. TAT-Pim1 (wt) enhances survival in a PI3-kinase-independent manner. Basophils were preincubated with the buffer (control), or with TAT-Pim1(wt) and TATPim1(KD) for 1 hour, and then wortmannin $(100 \mathrm{nM})$ or LY2940002 $(30 \mu \mathrm{M})$ was added to cell cultures for 24 hours as indicated. (A) Cell apoptosis was determined by annexin V-FITC staining and subsequent flow cytometry. Apoptotic cells are shown as percentage of annexin V-positive cells. Data are presented as mean plus SEM from 3 experiments. ${ }^{\star} P<.05,{ }^{* \star} P<.01$, for the comparison of TAT-Pim1 versus medium control within the groups, by one-way ANOVA. (B) Activation of caspase 3 was assessed by immunoblotting measuring procaspase 3 proteolytic cleavage. TAT-Pim1 fusion proteins were detected using anti-HA antibody. $\beta$-Actin was used as loading control. The level of the activated caspase 3 was estimated in each sample by densitometry. Fold change of caspase 3 activity was calculated as described in the legend to Figure 4. (C) Phospho- and total of p38 MAPK were detected using specific antibodies. Fold change of p38 MAPK phosphorylation was calculated as relative ratio of the band intensity value of phosphorylated p38 MAPK in individual sample divided by the band intensity value of phosphorylated p38 MAPK from control basophils incubated in medium alone. The band intensity value of phosphorylated p38 MAPK was normalized to the band intensity value of total p38.

cell-death repressors, such as Bcl- $\mathrm{X}_{\mathrm{L}}$, Mcl-1, IAP2, and XIAP. Basophils, however, express Bcl-2 at high levels close to that found in relatively long-lived T cells (S.A.D., unpublished data, May 2007). Thus, the abundance of Bcl-2 may not only confer a high resistance of basophils to apoptosis in vitro but also lead to a relatively long life span in vivo. The observation that basophils passively sensitized in vivo by low amounts specific IgE respond to the appropriate allergen within up to 2 weeks supports this idea. ${ }^{54}$

Our data show that spontaneous apoptosis of basophils operates through a caspase-dependent mechanism. It is associated with catalytic processing of caspase 3 into its active form (p17/p12 dimer) and the subsequent cleavage of caspase 3 intracellular substrates, PARP and Bcl-2. The pivotal role of caspase 3 as an executioner caspase in basophils is further
A
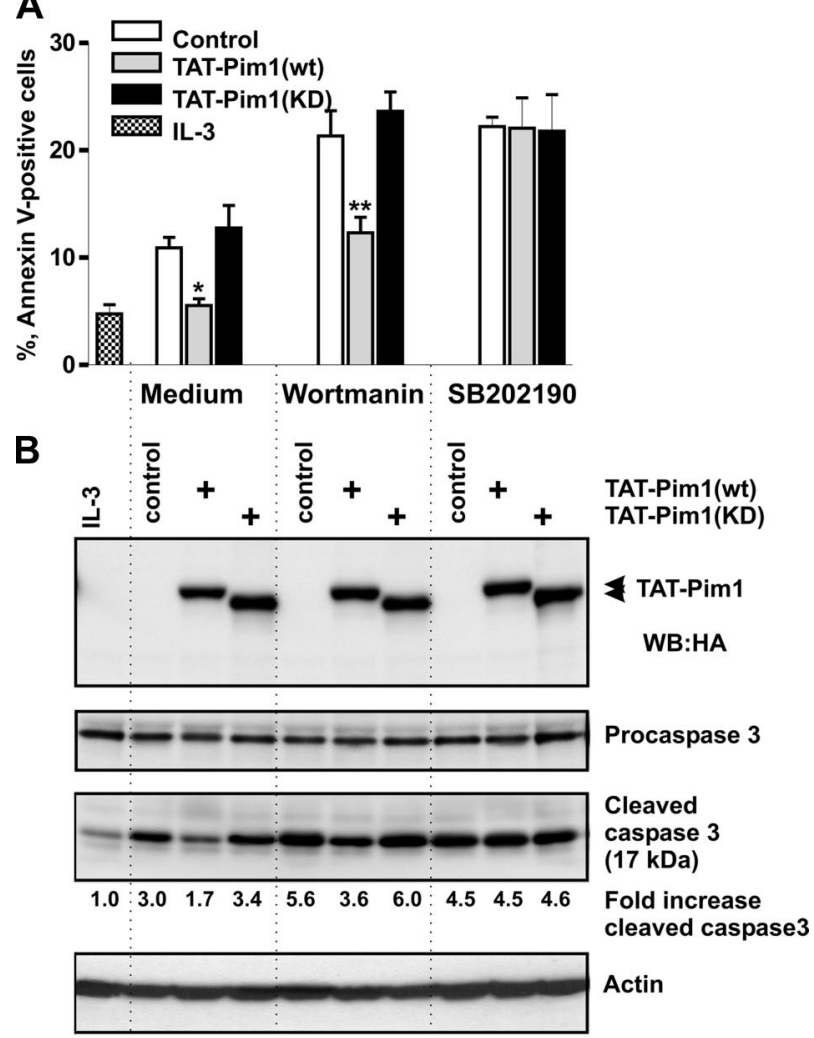

C

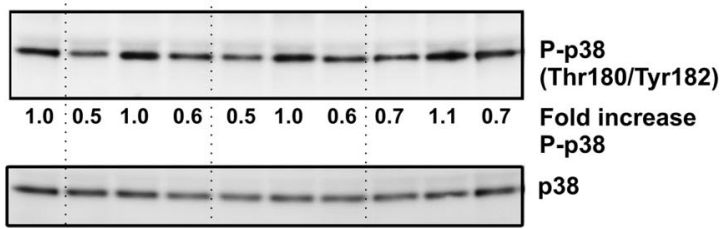

Figure 6. Antiapoptotic effect of TAT-Pim1(wt) depends on p38 MAPK activation. Basophils were incubated with the buffer (control), or with TAT-Pim1 $1(\mathrm{wt})$ and TAT-Pim1(KD) for 1 hour, and then wortmannin $(100 \mathrm{nM})$ or SB202190 $(10 \mu \mathrm{M})$ was added to cell cultures for 24 hours. (A) Cell apoptosis was determined by annexin V-FITC staining and subsequent flow cytometry. Apoptotic cells are shown as percentage of annexin $\mathrm{V}$-positive cells. Data are shown as mean plus SEM from 3 experiments. ${ }^{\star} P<.05,{ }^{\star \star} P<.01$, for the comparison of TAT-Pim1 versus medium control within the groups, by one-way ANOVA. (B) Activated caspase 3, procaspase 3 , and TAT-pim1 fusion proteins as well as (C) phospho-and total of p38 MARK were detected by immunblotting using specific antibodies. $\beta$-Actin was used as loading control. Fold changes of caspase 3 activity and p38 MAPK phosphorylation were calculated as described in the legends to Figures 4 and 5 .

supported by the fact that zVAD-fmk inhibits spontaneous apoptosis and blocks the cleavage of PARP and Bcl-2. Caspase 3-dependent cleavage of Bcl-2 to the proapoptotic Bax-like death effector $(23 \mathrm{kDa}),{ }^{55}$ which is a relatively early event in the apoptotic cascade, ${ }^{56}$ has been reported to act as a positive amplification loop on the release of cytochrome $c$ and full activation of caspases. ${ }^{57}$ Thus, the Bcl-2 cleavage observed during spontaneous basophil apoptosis suggests that mitochondria might be critical in this death pathway. As Bcl-2 appears to play both anti- and proapoptotic roles, it is probable that the ratio of full-length Bcl-2 and its cleaved form might be crucial for the commitment of basophils to apoptosis.

In agreement with previous studies, ${ }^{1-6}$ we find that IL-3, IL-5, and GM-CSF, which share a common receptor $\beta$-chain that is required for signal transduction, prolong granulocyte survival in granulocyte typerestricted manner. Only IL-3 is capable of effectively enhancing basophil survival, although basophils express functional receptor $\alpha$-chains 
for all 3 cytokines. ${ }^{44,58}$ Although the basis of this exclusive antiapoptotic activity of IL-3 remains to be clarified, we do find differences in the effects of the 3 cytokines of the GM-CSF subfamily on signaling events that may contribute to cell survival. In contrast to IL-5, which promotes only transient Stat 5/3 activation, IL-3 causes a sustained activation of Stat 5 (Figures 2B, 3B, S1) and much stronger initial activation of Stat 3 (Figure S1) that is associated with the up-regulation or de novo induction of several antiapoptotic proteins, including Bcl- $\mathrm{X}_{\mathrm{L}}, \mathrm{Mcl}-1$, and Pim1. In addition, IL-3 induces more prolonged activation of PKB (Figure S1). Thus, such differences in signaling strength and/or duration are a probable reason for the distinct effectiveness of the GM-CSF family members in supporting basophil survival. The sustained expression of Pim1, which is a rapidly degraded protein, ${ }^{59}$ might be particularly important. By screening a large number of other cytokines, which can be produced by activated mast cells and $\mathrm{T}$ lymphocytes at sites of allergic inflammation, we further show that the antiapoptotic action of IL-3 is unique, suggesting a very restricted regulation of basophil survival in vivo.

Growth factor-mediated signals directly support cell survival by increasing the transcription of the prosurvival proteins ${ }^{60}$ as well as by inducing phosphorylation cascades that inhibit the activities of proapoptotic proteins. ${ }^{61}$ A PI3-kinase/Akt-dependent signaling pathway has been shown to play a pivotal role in protecting cells from apoptosis. ${ }^{61}$ Our finding that the 2 commonly used PI3-kinase inhibitors, wortmannin and LY294002, exert similar negative effects on the survival of basophils cultured in serum-containing medium without cytokine is consistent with the critical role of PI3-kinase in the regulation of spontaneous basophil apoptosis. Our efforts to delineate the molecular mechanisms responsible for the IL-3-mediated protection of basophils from apoptosis revealed the importance of Pim1 kinase, a known transcriptional target of different hematopoietic growth factors. ${ }^{37,62}$ The observations that IL-3 induces a rapid and sustained expression of Pim1 protein and that the levels of Pim1 expression reflect the degree of cytokine-enhanced survival suggested a potential antiapoptotic role of Pim1 in basophils, and protein transduction experiments provided a direct proof. Transduction of basophils with TAT-Pim1(KD) kinase dead mutant inhibits IL-3-mediated survival, whereas TAT-Pim1(wt) enhances survival of basophils deprived of IL-3. The observations that stimulation with IL-3 or transduction with TAT-Pim1(wt) render basophils less sensitive to wortmannin than to LY2940002 suggest that Pim1 contributes to IL-3-induced cell survival in parallel and independently of PI3-kinase. The recent finding that LY294002 inhibits the catalytic activity of Pim1 and the observation that IL-3-induced Pim1 protein expression in basophils is independent on PI3-kinase signaling (Figure 3) fully support this idea. Thus, this study provides the first evidence for an important functional role of Pim1 kinase in primary nondividing human blood cells. Furthermore, our finding that this protein is induced in all granulocyte subtypes by prosurvival cytokines of the GM-CSF family (Figures 2F, S2) suggests that Pim1 might be part of a cytokine-mediated antiapoptotic signaling mechanism that is not restricted to a particular granulocyte type. Recent data indicating that GM-CSF induces in neutrophils a Ly294002-sensitive antiapoptotic pathway, which is not sensitive to pharmacologic inhibition of Akt supports this idea. ${ }^{63}$

Relatively little is known about Pim1 downstream targets, and most of them have been implicated in the regulation of proliferation rather than cell survival. Recent work has established a direct functional role for Pim kinases to prevent cell death by serine112 phosphorylation, thereby inactivating proapoptotic activity of Bad. ${ }^{64}$ As basophils express very low levels of Bad, and we were unable to detect Bad phosphorylation on serine residues S112 and S136 in IL-3-stimulated cells (S.A.D., unpublished data, October
2007), it is rather improbable that Bad is a key mediator of apoptosis in basophils. This notion is consistent with data obtained in IL-3-dependent cell lines, showing that apoptosis induced by cytokine withdrawal does not correlate with the phosphorylation status of Bad. ${ }^{21,65}$

p38 MAPK has been implicated as a positive or negative regulator of cell survival, depending on the type of cells studied, ${ }^{66}$ and there is increasing evidence for a prosurvival role of p38 in human neutrophils and eosinophils. ${ }^{19,52,67}$ Searching for potential targets that regulate survival downstream of Pim1, we found that, in basophils deprived of IL-3, Tat-Pim1(wt) caused an increase in activating phosphorylation of p38 at Thr180/Tyr182 residues similar to that seen in IL-3-stimulated cells. Blocking p38 MAPK activity with the specific inhibitor, SB202190, abrogated the antiapoptotic effect of Tat-Pim1(wt) and further accelerated apoptosis to the level seen in control cells. These data suggest that p38 MAPK activity is required for the Pim1-mediated survival response. Given that p38 has been implicated in the activation of transcriptional factors, including NF- $\mathrm{BB}$, it is conceivable that NF- $\mathrm{B}-$ dependent transcription might contribute to Pim1-dependent basophil survival. The recent finding that induction of Pim 2 in lymphocytes leads to the activation of NF- $\mathrm{KB}$ enhancing their survival ${ }^{68}$ would be in line with this hypothesis. Alternatively, p38 may also play a prosurvival role by phosphorylating caspase 8 and 3, thereby impairing their activity as recently shown in neutrophils. ${ }^{52}$ Pim1, however, cannot directly activate p38 MAPK because the regulatory Thr-Xaa-Tyr site of p38 does not resemble the consensus sequence for Pim1 substrate recognition. Therefore, Pim1 probably phosphorylates a yet undefined positive upstream regulator of the $\mathrm{p} 38 \mathrm{MAPK}$ signaling pathway.

In conclusion, our data provide first insights into key molecules and intracellular events that regulate survival and apoptosis in human basophils. We show that IL-3 is an efficient and unique survival factor for basophils that induces a PI3kinase-independent and Pim1-dependent survival pathway. The study provides a first example for a functional role of Pim1 kinase in primary nondividing human cells. Because Pim1 ablation results in only a very weak phenotype, at least in mice, ${ }^{69}$ pharmacologic inhibition of Pim-kinase activity may offer a novel approach to target the survival of basophils, and possibly other effector cell types, such as eosinophils, at sites of allergic inflammation.

\section{Acknowledgments}

The authors thank B. Turk and A. Bullok for Pim1 cDNAs and S. Dowdy for the pTAT 2.1 expression vector.

This study was supported by the Swiss National Science Foundation, and in part by the Stiftung 3R (\#84-02) and CSL Ltd Australia.

\section{Authorship}

Contribution: S.A.D. designed and performed the research and prepared the paper; N.S. assisted with flow cytometry; T.B. contributed to the design and interpretation of experiments; and C.A.D designed research and wrote the paper.

Conflict-of-interest disclosure: The authors declare no competing financial interests.

Correspondence: Clemens A. Dahinden, Institute of Immunology, University of Bern, Inselspital, CH-3010 Bern, Switzerland; e-mail: Clemens.dahinden@iib.unibe.ch. 


\section{References}

1. Rothenberg ME, Owen WF Jr, Silberstein DS, et al. Human eosinophils have prolonged survival, enhanced functional properties, and become hypodense when exposed to human interleukin 3. J Clin Invest. 1988;81:1986-1992.

2. Rothenberg ME, Petersen J, Stevens RL, et al. IL-5-dependent conversion of normodense human eosinophils to the hypodense phenotype uses 3T3 fibroblasts for enhanced viability, accelerated hypodensity, and sustained antibody-dependent cytotoxicity. J Immunol. 1989;143:23112316.

3. Simon HU, Yousefi S, Dibbert B, Levi-Schaffer F, Blaser K. Anti-apoptotic signals of granulocytemacrophage colony-stimulating factor are transduced via Jak2 tyrosine kinase in eosinophils. Eur J Immunol. 1997;27:3536-3539.

4. Brach MA, deVos S, Gruss HJ, Herrmann F. Prolongation of survival of human polymorphonuclear neutrophils by granulocyte-macrophage colony-stimulating factor is caused by inhibition of programmed cell death. Blood. 1992;80:29202924.

5. Yamaguchi M, Hirai K, Morita Y, et al. Hemopoietic growth factors regulate the survival of human basophils in vitro. Int Arch Allergy Immunol. 1992; 97:322-329.

6. Zheng X, Karsan A, Duronio V, et al. Interleukin-3, but not granulocyte-macrophage colony-stimulating factor and interleukin-5, inhibits apoptosis of human basophils through phosphatidylinositol 3-kinase: requirement of NF-kappaB-dependent and -independent pathways. Immunology. 2002; 107:306-315.

7. Moulding DA, Quayle JA, Hart CA, Edwards SW. $\mathrm{Mcl}-1$ expression in human neutrophils: regulation by cytokines and correlation with cell survival. Blood. 1998;92:2495-2502.

8. Chuang PI, Yee E, Karsan A, Winn RK, Harlan $\mathrm{JM}$. A1 is a constitutive and inducible Bcl-2 homologue in mature human neutrophils. Biochem Biophys Res Commun. 1998;249:361-365.

9. Dibbert B, Daigle I, Braun D, et al. Role for Bcl-xL in delayed eosinophil apoptosis mediated by granulocyte-macrophage colony-stimulating factor and interleukin-5. Blood. 1998;92:778-783.

10. Vassina EM, Yousefi S, Simon D, Zwicky C, Conus S, Simon HU. clAP-2 and survivin contribute to cytokine-mediated delayed eosinophil apoptosis. Eur J Immunol. 2006;36:1975-1984.

11. Altznauer F, Martinelli S, Yousefi S, et al. Inflammation-associated cell cycle-independent block of apoptosis by survivin in terminally differentiated neutrophils. J Exp Med. 2004;199:13431354.

12. Hasegawa T, Suzuki K, Sakamoto C, et al. Expression of the inhibitor of apoptosis (IAP) family members in human neutrophils: up-regulation of cIAP2 by granulocyte colony-stimulating factor and overexpression of cIAP2 in chronic neutrophilic leukemia. Blood. 2003;101:1164-1171.

13. Epling-Burnette PK, Zhong B, Bai F, et al. Cooperative regulation of Mcl-1 by Janus kinase/stat and phosphatidylinositol 3-kinase contribute to granulocyte-macrophage colony-stimulating factor-delayed apoptosis in human neutrophils. J Immunol. 2001;166:7486-7495.

14. Weinmann P, Gaehtgens P, Walzog B. Bcl-XIand Bax-alpha-mediated regulation of apoptosis of human neutrophils via caspase-3. Blood. 1999; 93:3106-3115.

15. Maianski NA, Mul FP, van Buul JD, Roos D, Kuijpers TW. Granulocyte colony-stimulating factor inhibits the mitochondria-dependent activation of caspase-3 in neutrophils. Blood. 2002;99:672679.

16. Klein JB, Rane MJ, Scherzer JA, et al. Granulocyte-macrophage colony-stimulating factor delays neutrophil constitutive apoptosis through phosphoinositide 3-kinase and extracellular signal-regulated kinase pathways. J Immunol. 2000; 164:4286-4291.

17. Yousefi S, Hoessli DC, Blaser K, Mills GB, Simon $\mathrm{HU}$. Requirement of Lyn and Syk tyrosine kinases for the prevention of apoptosis by cytokines in human eosinophils. J Exp Med. 1996;183:14071414.

18. Pazdrak K, Olszewska-Pazdrak B, Stafford S, Garofalo RP, Alam R. Lyn, Jak2, and Raf-1 kinases are critical for the antiapoptotic effect of interleukin 5, whereas only Raf-1 kinase is essential for eosinophil activation and degranulation. J Exp Med. 1998;188:421-429.

19. Villunger A, O'Reilly LA, Holler N, Adams J, Strasser A. Fas ligand, Bcl-2, granulocyte colonystimulating factor, and p38 mitogen-activated protein kinase: regulators of distinct cell death and survival pathways in granulocytes. J Exp Med. 2000;192:647-658.

20. del Peso L, Gonzalez-Garcia M, Page C, Herrera $R$, Nunez G. Interleukin-3-induced phosphorylation of BAD through the protein kinase Akt. Science. 1997;278:687-689.

21. Ekert PG, Jabbour AM, Manoharan A, et al. Cell death provoked by loss of interleukin-3 signaling is independent of Bad, Bim, and PI3 kinase, but depends in part on Puma. Blood. 2006;108:1461 1468.

22. Ekoff M, Kaufmann T, Engstrom M, et al. The $\mathrm{BH} 3-o n l y$ protein Puma plays an essential role in cytokine deprivation induced apoptosis of mast cells. Blood. 2007;110:3209-3217.

23. Guthridge MA, Barry EF, Felquer FA, et al. The phosphoserine-585-dependent pathway of the GM-CSF/IL-3/IL-5 receptors mediates hematopoietic cell survival through activation of NF-kappaB and induction of bcl-2. Blood. 2004;103:820827

24. Kops GJ, de Ruiter ND, De Vries-Smits AM, Powell DR, Bos JL, Burgering BM. Direct control of the Forkhead transcription factor AFX by protein kinase B. Nature. 1999;398:630-634.

25. Toker A, Cantley LC. Signalling through the lipid products of phosphoinositide-3-OH kinase. Nature. 1997;387:673-676.

26. Kennedy SG, Wagner AJ, Conzen SD, et al. The PI 3-kinase/Akt signaling pathway delivers an anti-apoptotic signal. Genes Dev. 1997;11:701713.

27. Hammerman PS, Fox CJ, Birnbaum MJ, Thompson CB. Pim and Akt oncogenes are independent regulators of hematopoietic cell growth and survival. Blood. 2005; 105:4477-4483.

28. Allen JD, Berns A. Complementation tagging of cooperating oncogenes in knockout mice. Semin Cancer Biol. 1996;7:299-306.

29. Wang Z, Bhattacharya N, Weaver M, et al. Pim-1 a serine/threonine kinase with a role in cell survival, proliferation, differentiation and tumorigenesis. J Vet Sci. 2001;2:167-179.

30. Bachmann M, Moroy T. The serine/threonine kinase Pim-1. Int J Biochem Cell Biol. 2005;37: 726-730.

31. Amaravadi $\mathrm{R}$, Thompson $\mathrm{CB}$. The survival kinases Akt and Pim as potential pharmacological targets. J Clin Invest. 2005;115:2618-2624.

32. Bullock AN, Debreczeni J, Amos AL, Knapp S, Turk BE. Structure and substrate specificity of the Pim-1 kinase. J Biol Chem. 2005;280:4167541682.

33. Fox CJ, Hammerman PS, Cinalli RM, Master SR, Chodosh LA, Thompson CB. The serine/threonine kinase Pim-2 is a transcriptionally regulated apoptotic inhibitor. Genes Dev. 2003;17:18411854.

34. Yip-Schneider MT, Horie M, Broxmeyer HE. Transcriptional induction of pim-1 protein kinase gene expression by interferon gamma and posttranscriptional effects on costimulation with steel factor. Blood. 1995;85:3494-3502.

35. Miura O, Miura $\mathrm{Y}$, Nakamura N, et al. Induction of tyrosine phosphorylation of Vav and expression of Pim-1 correlates with Jak2-mediated growth signaling from the erythropoietin receptor. Blood. 1994;84:4135-4141.

36. Rui H, Xu J, Mehta S, et al. Activation of the Jak2 Stat5 signaling pathway in Nb2 lymphoma cells by an anti-apoptotic agent, aurintricarboxylic acid. J Biol Chem. 1998;273:28-32.

37. Stout BA, Bates ME, Liu LY, Farrington NN, Bertics PJ. IL-5 and granulocyte-macrophage colony-stimulating factor activate STAT3 and STAT5 and promote Pim-1 and cyclin D3 protein expression in human eosinophils. J Immunol. 2004;173:6409-6417.

38. Tschopp CM, Spiegl N, Didichenko S, et al. Granzyme B, a novel mediator of allergic inflammation: its induction and release in blood basophils and human asthma. Blood. 2006;108:2290-2299.

39. Taylor SS. cAMP-dependent protein kinase: model for an enzyme family. J Biol Chem. 1989; 264:8443-8446.

40. Palaty CK, Clark-Lewis I, Leung D, Pelech SL. Phosphorylation site substrate specificity determinants for the Pim-1 protooncogene-encoded protein kinase. Biochem Cell Biol. 1997;75:153-162.

41. Ochensberger B, Daepp GC, Rihs S, Dahinden CA. Human blood basophils produce interleukin-13 in response to IgE-receptor-dependent and -independent activation. Blood. 1996;88: 3028-3037.

42. Yoshimura-Uchiyama $C$, Yamaguchi M, Nagase $\mathrm{H}$, et al. Comparative effects of basophil-directed growth factors. Biochem Biophys Res Commun. 2003;302:201-206.

43. Bischoff SC, Dahinden CA. Effect of nerve growth factor on the release of inflammatory mediators by mature human basophils. Blood. 1992;79: 2662-2669.

44. Bischoff SC, Brunner T, De Weck AL, Dahinden CA. Interleukin 5 modifies histamine release and leukotriene generation by human basophils in response to diverse agonists. J Exp Med. 1990; 172:1577-1582.

45. Miura K, Saini SS, Gauvreau G, MacGlashan DW $J$ r. Differences in functional consequences and signal transduction induced by IL-3, IL-5, and nerve growth factor in human basophils. J Immunol. 2001;167:2282-2291.

46. Daigle I, Simon HU. Critical role for caspases 3 and 8 in neutrophil but not eosinophil apoptosis. Int Arch Allergy Immunol. 2001;126:147-156.

47. Lavastre V, Chiasson S, Cavalli H, Girard D. Viscum album agglutinin-I induces apoptosis and degradation of cytoskeletal proteins via caspases in human leukaemia eosinophil AML14.3D10 cells: differences with purified human eosinophils. Br J Haematol. 2005; 130:527-535.

48. Letuve S, Druilhe A, Grandsaigne M, Aubier M, Pretolani M. Involvement of caspases and of mitochondria in Fas ligation-induced eosinophil apoptosis: modulation by interleukin- 5 and interferon-gamma. J Leukoc Biol. 2001;70:767-775.

49. Sanghavi DM, Thelen M, Thornberry NA, Casciola-Rosen L, Rosen A. Caspase-mediated proteolysis during apoptosis: insights from apoptotic neutrophils. FEBS Lett. 1998;422:179-184.

50. Jacobs MD, Black J, Futer O, et al. Pim-1 ligandbound structures reveal the mechanism of serine/ threonine kinase inhibition by LY294002. J Biol Chem. 2005;280:13728-13734

51. Nagahara H, Vocero-Akbani AM, Snyder EL, et al. Transduction of full-length TAT fusion proteins into mammalian cells: TAT-p27Kip1 induces cell migration. Nat Med. 1998;4:1449-1452. 
52. Alvarado-Kristensson $M$, Melander $F$, Leandersson K, Ronnstrand L, Wernstedt C, Andersson T. p38-MAPK signals survival by phosphorylation of caspase- 8 and caspase- 3 in human neutrophils. J Exp Med. 2004;199:449458.

53. Yoshimura C, Miyamasu M, Nagase H, et al. Glucocorticoids induce basophil apoptosis. J Allergy Clin Immunol. 2001;108:215-220.

54. Johansson SG, Nopp A, van Hage M, et al. Pas sive IgE-sensitization by blood transfusion. Allergy. 2005;60:1192-1199.

55. Cheng EH, Kirsch DG, Clem RJ, et al. Conversion of Bcl-2 to a Bax-like death effector by caspases. Science. 1997;278:1966-1968.

56. Fadeel B, Hassan Z, Hellstrom-Lindberg E Henter JI, Orrenius S, Zhivotovsky B. Cleavage of $\mathrm{Bcl}-2$ is an early event in chemotherapy-induced apoptosis of human myeloid leukemia cells. Leukemia. 1999;13:719-728.

57. Kirsch DG, Doseff A, Chau BN, et al. Caspase-3dependent cleavage of $\mathrm{Bcl}-2$ promotes release of cytochrome c. J Biol Chem. 1999;274:2115521161.

58. Ochensberger B, Tassera L, Bifrare D, Rihs S,
Dahinden CA. Regulation of cytokine expression and leukotriene formation in human basophils by growth factors, chemokines and chemotactic agonists. Eur J Immunol. 1999;29:11-22.

59. Shay KP, Wang Z, Xing PX, McKenzie IF, Magnuson NS. Pim-1 kinase stability is regulated by heat shock proteins and the ubiquitin-proteasome pathway. Mol Cancer Res. 2005;3:170-181.

60. Cory S, Adams JM. The Bcl2 family: regulators of the cellular life-or-death switch. Nat Rev Cancer. 2002;2:647-656

61. Nicholson KM, Anderson NG. The protein kinase B/Akt signalling pathway in human malignancy. Cell Signal. 2002;14:381-395.

62. Lilly M, Le T, Holland P, Hendrickson SL. Sustained expression of the pim-1 kinase is specifically induced in myeloid cells by cytokines whose receptors are structurally related. Oncogene. 1992;7:727-732.

63. Martinelli S, Kostylina G, Niggli V, et al. Targeting survivin via PI3K but not c-akt/PKB by anticancer drugs in immature neutrophils. Oncogene. 2006; 25:6915-6923

64. Aho TL, Sandholm J, Peltola KJ, Mankonen HP,
Lilly M, Koskinen PJ. Pim-1 kinase promotes inactivation of the pro-apoptotic Bad protein by phosphorylating it on the Ser112 gatekeeper site. FEBS Lett. 2004;571:43-49.

65. Hinton HJ, Welham MJ. Cytokine-induced protein kinase $B$ activation and Bad phosphorylation do not correlate with cell survival of hemopoietic cells. J Immunol. 1999;162:7002-7009.

66. Nebreda AR, Porras A. p38 MAP kinases: beyond the stress response. Trends Biochem Sci. 2000; 25:257-260.

67. Zhang JP, Wong CK, Lam CW. Role of caspases in dexamethasone-induced apoptosis and activation of c-Jun NH2-terminal kinase and p38 mitogen-activated protein kinase in human eosinophils. Clin Exp Immunol. 2000;122:20-27.

68. Hammerman PS, Fox CJ, Cinalli RM, et al. Lymphocyte transformation by Pim-2 is dependent on nuclear factor-kappaB activation. Cancer Res. 2004;64:8341-8348

69. Domen J, van der Lugt NM, Laird PW, et al. Impaired interleukin-3 response in Pim-1-deficient bone marrow-derived mast cells. Blood. 1993;82: 1445-1452. 